\title{
CARTOGRAFIA E DIREITOS HUMANOS NA ESCOLA PÚBLICA - NOVAS PRÁTICAS NO ESTÁGIO SUPERVISIONADO EM GEOGRAFIA NA UEG - UnU ITAPURANGA(GO)
}

\author{
Ana Carolina de Oliveira Marques \\ Universidade Estadual de Goiás, Curso de Geografia, Itapuranga, GO, Brasil. \\ carol.geografia@hotmail.com
}

\begin{abstract}
RESUMO
Partimos do pressuposto de Miguel Arroyo: a escola pública tem o dever ético-políticopedagógico de oferecer aos "trabalhadores que estudam" as condições de se entenderem vítimas das injustiças sociais que lhes roubam a humanidade, forjando-lhes sujeitos sem direito a ter direitos. Este é um dos princípios balizadores da formação de professores em Geografia na Universidade Estadual de Goiás, Unidade Itapuranga (Goiás). A oficina "Cartografia e Direitos Humanos" realizada em uma das escolas-campo - a Escola Estadual Zico Coelho - sintetiza o esforço em formar professores com princípios políticopedagógicos sensíveis aos "itinerários humanos" dos educandos; às múltiplas violências das quais são vítimas; aos seus cotidianos enquanto trabalhadores/as - inclusive na infância; aos saberes adquiridos nas experiências radicais de vida. A oficina fora conduzida por estagiários do $6^{\circ}$ período de licenciatura. Apresentamos, neste texto, todo o percurso dos estagiários desde a preparação teórico-conceitual, a definição da metodologia e os resultados da intervenção pedagógica. Esperamos que as reflexões compartilhadas agreguem às pedagogias afirmativas do vínculo radical entre educação geográfica, formação de professores e justiça social.
\end{abstract}

Palavras-chave: Justiça social. Educação Geográfica. Formação de professores.

\section{CARTOGRAPHY AND HUMAN RIGHTS ON PUBLIC SCHOOL - NEW APPROACHES ON SUPERVISED INTERNSHIP IN SCHOOL OF GEOGRAPHY AT UEG/UnU ITAPURANGA (GO)}

\begin{abstract}
Considering the assumption of Miguel Arroyo (2017): public schools have the ethic politic pedagogic duty to offer to the "labors who study" the conditions to recognize themselves as victims of social injustice that steal their humanity, forging individuals with no permission to have rights. This is one of the main principles of the geography professors training program at the Goias State University (UEG), located in Itapuranga city (Goias). The "Cartography and Human Rights" seminar that took place in one of the local partner schools - the Zico Coelho State School - synthetizes the effort on professors training program with politics pedagogic principles with sensitivity to the students "human routes", to the multiple violence which they are victims, to their labor's routine even during their childhood, and to their knowledge obtained at extreme life experiences. The seminar was carried on by grad students from the 6th semester of the licentiate degree course. In this text, we introduce all the grad students' journeys, since conceptual theoric setup, methodology definition, and results of a pedagogic intervention. We hope that those shared ideas contribute to affirmative pedagogies of radical connection between geographic education, professors training, and social justice.
\end{abstract}

Keywords: Social Justice. Geographic Education. Professors Training.

\section{INTRODUÇÃO}

Escrevemos a todos envolvidos na formação docente: estagiários, orientadores de estágio (docentes que conduzem, de perto, os licenciandos na ação investigativa da realidade escolar e na iniciação à docência), demais docentes dos cursos de licenciatura, professores da educação básica, gestores escolares, elaboradores de políticas educacionais.

Este texto deriva da experiência de orientação do estágio supervisionado no curso de licenciatura plena em Geografia na Universidade Estadual de Goiás/Unidade Itapuranga, no último triênio. 
Experiência na qual confrontamos, entre outras acepções equivocadas, o entendimento do estágio como atividade exclusivamente prática, como "saber fazer". O que aqui se apresenta deriva do esforço de afirmação da pesquisa e da indissociabilidade teoria/prática no estágio docência, algo já reivindicado por pensadores desde a década de 1990, a exemplo de Pimenta, Lima e Katuta.

Não garantimos que este ensaio abrigue ideias inéditas, afinal, a produção do conhecimento é histórica e coletiva. Também não se trata de um relato de experiência esvaziado de reflexão. Tratase, sim, do confronto entre teorias (universais) e a experiência singular desenvolvida junto ao coletivo da Escola Estadual Zico Coelho, exercício que se nos apresenta indispensável ao fortalecimento da práxis formativa do professor.

Vale ainda mencionar, a título de introdução, dois projetos de pesquisa, cujos avanços teóricos e metodológicos incidem neste trabalho. Tratam-se dos projetos "Desenvolvimento Territorial e Sociobiodiversidade: perspectiva para o Mundo do Cerrado ${ }^{1}$ (CAPES, 411)" e "Para além da BNCC: Itinerários humanos e Educação Geográfica em escolas públicas no município de Itapuranga $(\mathrm{GO})^{2 \text { ". }}$.

No primeiro, interpela-se o Cerrado enquanto território em disputa: econômica, política, cultural e de narrativas. Entendemos que a compreensão do desenvolvimento territorial do Cerrado exige o discernimento dos sujeitos/coletivos e territorialidades que pautam as políticas territoriais: os discursos autorizados. Nesse sentido, sendo a educação um campo da vida social imerso na totalidade, ele é também permeado pelos acontecimentos da conjuntura política e econômica, o que demanda dos educadores e educadoras uma atenção especial a estas questões. Ainda mais, quando se reconhecem defensores dos direitos humanos.

No outro projeto, colamos em evidência as contradições entre as "diretrizes" curriculares impostas pela nova Base Nacional Comum Curricular (BNCC) e os princípios de uma educação plural, democrática e libertadora. Falar em educação e direitos humanos no contexto atual passa, pois, por questionar radicalmente a reforma empresarial da educação em curso, na qual a BNCC cumpre um papel importante.

Dados os esclarecimentos introdutórios, reiteramos: a defesa da escola pública enquanto veículo de proteção, promoção e reparação dos direitos humanos está no cerne deste trabalho. Esperamos que, além do registro da nossa intervenção pedagógica, o mesmo some às pedagogias afirmativas do vínculo radical entre educação geográfica, formação de professores e justiça social.

\title{
CARTOGRAFIA DE UM COMEÇO
}

Diante da insegurança quanto a uma concepção tácita entre autora e leitores, iniciamos com o conceito de estágio que rege as nossas práticas:

\begin{abstract}
Entendemos que o estágio se constitui como um campo de conhecimento, o que significa atribuir-Ihe um estatuto epistemológico que supera sua tradicional redução à atividade prática instrumental. Enquanto campo de conhecimento, o estágio se produz na interação dos cursos de formação com o campo social no qual se desenvolvem as práticas educativas. Nesse sentido, o estágio poderá se constituir em atividade de pesquisa (PIMENTA e LIMA, 2005 p. 6).
\end{abstract}

Apesar da numerosa produção acerca do estágio e do seu papel na Educação formal, estudiosos (REGO e COSTELA, 2019; ARROYO, 2017) apontam a fragilidade de uma leitura sociopolítica que localize a escola e a ação pedagógica para além dos muros burocrático-institucionais. Que posicione a escola no mundo, sobretudo, no mundo do trabalho. Por essas e outras, insistimos na importância da pesquisa - intra e extra classe - como informativo da teoria pedagógica e geográfica.

Extraímos, da leitura desses críticos, certas premissas para a condução do estágio, na busca por coerência entre a nossa ação e os "itinerários humanos" de estagiários e secundaristas de classes populares. A principal das premissas: a escola pública tem o dever ético-político-pedagógico de oferecer aos "trabalhadores que estudam" as condições de se entenderem vítimas das injustiças

\footnotetext{
${ }^{1}$ Projeto interinstitucional (UFG, UFU e UFT). Coordenação: Dr. Eguimar Felício Chaveiro (IESA/UFG).

2 Projeto submetido à Pró-Reitoria de Pesquisa da Universidade Estadual de Goiás. Códido: 4717. Coordenação: Dra Ana Carolina de O. Marques
} 
sociais que Ihes roubam a humanidade, forjando-lhes sujeitos sem direito a ter direitos (ARROYO, 2017).

No início da orientação do estágio, notamos o inverso do postulado de Arroyo. As narrativas dos estagiários com frequência resgatavam o "mito ôntico de inferioridade" das classes populares, culpabilizando os secundaristas pelo fracasso escolar (ARROYO, 2017). Legitimavam, de forma não consciente - talvez no impulso de distribuírem o que receberam em seus percursos escolares -, a degradação da estima dos trabalhadores e seus filhos(as): incapazes, violentos, indisciplinados, não educáveis.

Notamos ainda que o trabalho não figurava como princípio educativo no imaginário dos futuros professores, ainda que em um contexto de trabalhadores-estagiários em escolas acolhedoras de trabalhadores-secundaristas. Ambos, estagiários e secundaristas, oriundos do campo e das periferias urbanas. Ambos, na rede pública de ensino. Ambos, familiarizados com a evasão escolar, o trabalho precário e a exclusão social.

Apesar das evidências entre educação, trabalho e justiça social, o campo do estágio se nos apresentava distante de tudo isso. No início, também comungávamos de uma compreensão formal, burocrática e "etapista" do estágio: observação, monitoria, semirregência, regência, projeto de intervenção. Planos quinzenas, caderno de assinaturas, fichas de liberação, miniaulas, tabela de horas complementares.

A observação restringia-se à contemplação da prática de ensino do professor-regente; a monitoria à produção de "lembrancinhas" em datas comemorativas na escola; a semirregência à elaboração e correção de provas; e, a regência, à reprodução de modelos de ensino que resultava em constrangimento geral (dos estagiários, secundaristas, professora-orientadora, professor-regente, gestores escolares).

Tais condutas informavam uma concepção de ensino calcada em modelos didáticos alheios às particularidades dos educandos e territórios. Sobre a problemática, Pimenta e Lima se posicionam:

O pressuposto dessa concepção [prática como imitação de modelos] é o de que a realidade do ensino é imutável e os alunos que frequentam a escola também o são. Idealmente concebidos, à escola, competiria ensiná-los, segundo a tradição. Não cabe, pois, considerar as transformações históricas e sociais decorrentes dos processos de democratização do acesso, que trouxe para a escola novas demandas e realidades sociais, com a inclusão de alunos até então marginalizados do processo de escolarização e dos processos de transformação da sociedade, de seus valores e das características que crianças e jovens vão adquirindo (2005, p.8, grifo nosso).

As críticas das autoras se espraiam por variados aspectos do estágio: o desvio de função dos estagiários na escola; as miniaulas como gregárias de uma perspectiva de ensino instrumental; a desastrosa desarticulação entre as disciplinas das matrizes curriculares dos cursos de formação de professores:

A perspectiva técnica no estágio gera um distanciamento da vida e do trabalho concreto que ocorre nas escolas, uma vez que as disciplinas que compõem os cursos de formação não estabelecem os nexos entre os conteúdos (teorias?) que desenvolvem e a realidade nas quais o ensino ocorre. (PIMENTA e LIMA, 2005 p. 10)

O distanciamento entre a realidade escolar e a formação de professores corrobora com as narrativas depreciativas da profissão docente: "na teoria é uma coisa, na prática é outra!". Distanciamento que implica em desconhecimento do "mundo da escola" e incapacidade de compreensão dos amplos processos - de privatização, de fragmentação do sujeito e captura da subjetividade, etc. - que conformam a escola como parte de uma totalidade. Vejamos a fala de uma egressa do curso de licenciatura:

Borboleta, F, 26 anos - Francamente, o estágio foi uma prova de que alguma coisa estava errada: comigo ou com os alunos. Bem, no fim das contas, fiquei com a primeira opção e nunca mais entrei em uma sala de aula. Às vezes penso que deveria ter me dedicado mais ao curso. Naquela época, era faculdade (trabalhos, provas, estágios), emprego (carga horária exaustiva), preparativos para meu casamento, enfim, quase fiquei louca. Talvez isso nem sirva de desculpa, então, simplesmente afirmo que faltou dedicação. Embora me sinta culpada, ainda posso 
acrescentar que a condição atual dos professores não é mais a de uma profissão almejada e, sim, uma necessidade. (OLIVEIRA e FIGUEIREDO, 2013 p. 124-125).

Borboleta desistira da licenciatura em Letras na Universidade Estadual de Goiás. Qualquer tentativa precipitada de simplificação dos motivos que a levaram a desistir seria leviana. Todavia, seu depoimento, longe de abrigar motivos sobrenaturais e inexplicáveis, sugere impedimentos concretos que orbitam sobre a formação docente e se radicalizam no estágio: formação acadêmica excessivamente burocrática, incompatibilidades entre o tempo de trabalho e o tempo dos estudos, desvalorização social da profissão docente. E mais: a "dedicação" ao casamento, provavelmente sucedida pela "dedicação" (leia-se trabalho não remunerado) aos cuidados da casa, dos filhos, dos idosos e das pessoas com deficiência na família, revela mais uma hierarquia que se impõe na trajetória escolar das mulheres. Disso, a culpabilização de si pelo fracasso escolar. Provavelmente, não o primeiro.

Após inúmeras reuniões da coordenação de estágio, com a colaboração dos colegas de colegiado e estudantes, deliberamos irromper com este círculo vicioso. Refizemos o projeto, desburocratizamos várias de suas "etapas", coletivizamos a maioria delas, reforçamos o papel elementar da pesquisa, convocamos o engajamento dos professores das disciplinas específicas, dispusemo-nos ao conhecimento da realidade escolar e, sobretudo, dos sujeitos que nela se encontram.

A resistência perante o novo partiu, especialmente, dos estagiários. Ajustes foram feitos conforme as críticas que nos chegavam. Algumas alterações, porém, foram mantidas a despeito do incômodo inevitável de qualquer alteração na ordem estabelecida.

A oficina "Cartografia e Direitos Humanos", relatada neste artigo, expressa as transformações no estágio e a nova postura que adotamos. Nos próximos tópicos, esmiuçamos todo o percurso dos estagiários desde a preparação teórico-conceitual, o levantamento de dados, a definição da metodologia, a produção do material didático à intervenção pedagógica. Aplicamos um efeito nas fotografias (exagero de contraste) para preservar a identidade dos participantes, alguns deles crianças e adolescentes.

\section{A REFORMA DO ESTÁGIO DOCENTE EM GEOGRAFIA}

Vale recuperar aspectos anteriores à realização da oficina, especialmente a nova forma e conteúdo da prática inicial do estágio: a observação.

A observação deixou de ser exclusivamente individual, quando o estagiário, em silêncio no fundo da sala, contemplava inerte a prática do professor-regente. Agora, grande parte da carga horária passa a ser cumprida por meio de trabalhos de campo coletivos (como o retratado na Figura 1), pautados na interação entre todos os sujeitos envolvidos no estágio docência. Estes antecederam a elaboração do projeto de intervenção que resultaria na oficina.

Figura 1 - Itapuranga (GO): trabalho de Campo na Escola Estadual Zico Coelho, 2019

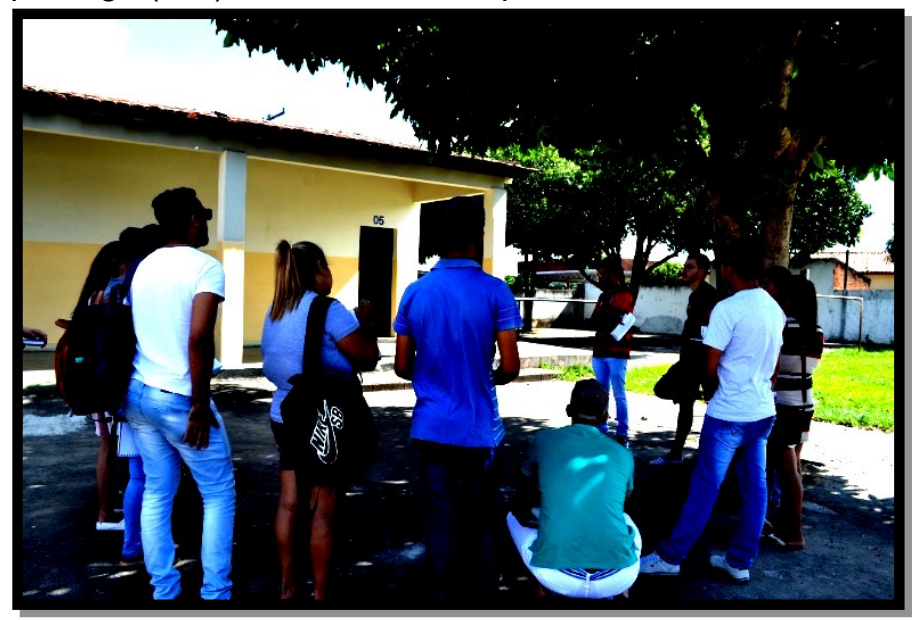

Fonte: MARQUES (2019). 
Em cada um dos três campos realizados, deu-se ênfase a um aspecto da realidade escolar: 1 . Espaço escolar, organização e gestão; 2. Carreira e movimento docente; 3. Educação Geográfica: desafios e perspectivas.

Percorremos toda a escola, da cozinha à biblioteca. Ouvimos o depoimento de professores, coordenadora pedagógica, diretora, secundaristas. Na caminhada, os estagiários socializavam diversas impressões: "sozinhos não teríamos acesso a todas essas informações"; "quando íamos sozinhos, a outra escola se recusava a nos mostrar o PPP"; "você viu que uma estudante está com o braço todo cortado? Ela mesma se cortava!"; "eu flagrei o momento em que um garoto praticou bullying com o colega! Você viu?". Narrativas que legitimavam o novo ponto de partida do estágio: a observação coletiva-investigativa da realidade escolar.

Segundo os termos defendidos por Pimenta e Lima, "a aproximação à realidade só tem sentido quando tem conotação de envolvimento, de intencionalidade, pois a maioria dos estágios burocratizados, carregados de fichas de observação, está numa visão míope de aproximação da realidade" (2005, p. 14).

Múltiplos temas emergiram nos trabalhos de campo: impedimentos à acessibilidade das pessoas com deficiência; bullying; recursos insuficientes para a merenda escolar; a injusta distribuição dos "gastos" entre as escolas militarizadas e não militarizadas; a vulnerabilidade socioeconômica dos estudantes; a carência de concurso público; os baixos salários; a importância e fragilidades dos sindicatos; a relação com a comunidade; os programas de bonificação docente; a resistência dos estudantes à linguagem cartográfica.

De volta à Universidade, durante as orientações extraclasse, mais impressões e fotografias socializadas. A partir dos cadernos de campo, montamos um "painel de problemas" na lousa, do qual partimos para a elaboração do projeto de intervenção pedagógica.

A Cartografia despontou como "conteúdo/problema". Outros temas, entretanto, pulsavam no painel e não podiam ser ignorados: abuso sexual, drogadição, periferia/segregação, violência, criminalidade. Percebemos que os temas apontavam para "marcadores de opressão" (TIBURI, 2018) que condenavam pobres, mulheres, negros, idosos, pessoas com deficiência aos "últimos degraus das hierarquias sociais" (ARROYO, 2017). Vimo-nos, pois, defronte ao debate dos direitos humanos.

Restava-nos interligar os dois grandes temas: Cartografia e Direitos Humanos. Com esse propósito, produzimos um bilhete (Figura 2) e o discutimos em sala de aula.

Figura 2 - UEG - Itapuranga (GO); "Bilhete" debatido na disciplina de Didática e Prática Docente em Geografia, 2019.

A Declaração Universal dos Direitos Humanos (ONU, 1948) completou, em 2019, 71 anos. A despeito disso, as violações crescem, sobretudo nos países periféricos do sistema capitalista submetidos a políticas neoliberais, coloniais e patriarcais (SANTOS, 2019). Concentração de terra e renda, precarização dos serviços de moradia, saúde e educação, elevadas taxas de homicídios de mulheres, negros e jovens, violência policial, desemprego, fome e insegurança alimentar, aumento da população de rua. As incipientes políticas sociais, implementadas desde a redemocratização do país, são duramente atacadas na atual conjuntura. Mas isso não é novo: as vítimas dessas violências foram, historicamente, expropriadas de seus territórios de vida, territórios estes negados nos discursos hegemônicos com o aporte de instrumentos como o mapa e o museu (ANDERSON, 2008). O mapa é, portanto, um discurso (vinculado a uma prática) sobre o território (GIRARDI, 2005). Precisamos disputá-lo.

Fonte: MARQUES (2019). 
Erguida a ponte entre Cartografia e Direitos Humanos, partimos à pesquisa bibliográfica, leitura, fichamentos e discussão de textos. Os debates se estendiam na disciplina "Didática e Prática Docente em Geografia I (Ensino fundamental)".

Realizamos um estudo sistemático da obra "Pedagogia do Oprimido" (2017) de Paulo Freire (Figura 3 ), a partir da qual definimos o nosso esteio pedagógico.

Figura 3 - UEG/Unu de Itapuranga (GO): leitura e discussão do texto "Pedagogia do Oprimido" - $6^{\circ}$ período de Licenciatura em Geografia, 2019.

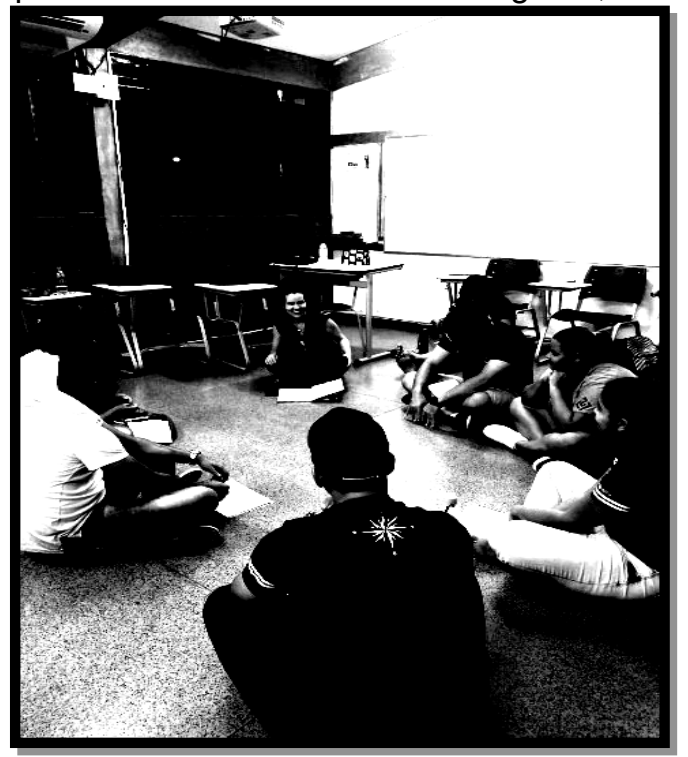

Fonte: MARQUES (2019).

O efeito performativo da leitura de Paulo Freire aproximou os "itinerários humanos" (ARROYO, 2017) ou "cartografias existenciais" (CHAVEIRO e VASCONCELLOS, 2018) dos estagiários aos dos secundaristas. As interpelações das próprias vivências e as associações com o que ouviam durante os trabalhos de campo, tornavam-se frequentes nos nossos diálogos. O encantamento se misturava ao incômodo em descobrir-se próximo do outro e desconhecedor(a) de si mesmo(a).

Ao se reconhecerem nos outros - trabalhadores, "corpos-segregados" - os estagiários ressignificavam suas trajetórias e destacavam as violências das quais foram vítimas. Aos poucos, entendiam a urgência dos educadores deixarem de ser "[...] meros espectadores dessas vivências cruéis dos educandos, assumindo seu dever profissional de trazê-las ao território dos currículos, buscando, em conjunto, com os próprios educandos/as, entender seus significados" (ARROYO, 2017 p. 15).

Chegamos ao consenso de que o "outro lado" da história, e da geografia, estavam ausentes nos currículos. Notamos a invisibilidade de inúmeros sujeitos e formas de vida. Desejamos então uma geografia do invisível, similar à "sociologia das ausências" de Boaventura Santos:

a sociologia das ausências é a pesquisa sobre os modos como o colonialismo, sob a forma de colonialismo de poder, de conhecimento e de ser, funciona em conjunto com o capitalismo e o patriarcado a fim de produzir exclusões abissais, ou seja, a fim de tornar certos grupos de pessoas e formas de vida social não-existentes, invisíveis, radicalmente inferiores ou radicalmente perigosos, em suma, descartáveis ou ameaçadores. (2019 p. 50).

Em Boaventura Santos, compreendemos também os limites da própria narrativa dos direitos humanos:

No amago dessa imaginação modernista existe a ideia de humanidade como totalidade construída com base num projeto comum: direitos humanos universais. Essa imaginação modernista, herdeira do humanismo renascentista, não conseguiu perceber que, uma vez combinado com o colonialismo, o capitalismo seria 
intrinsecamente incapaz de abdicar do conceito do sub-humano enquanto parte integrante da humanidade, ou seja, a ideia de que existem alguns grupos sociais cuja existência social não pode ser regida pela tensão entre regulação e emancipação [sociabilidade metropolitana], simplesmente porque não são completamente humanos. [...] Os mecanismos evoluíram no tempo, mas mantêm-se estruturalmente semelhantes aos do colonialismo histórico, nomeadamente, aqueles que envolvem regulação violenta sem a contrapartida da emancipação [sociabilidade colonial]. São eles o Estado colonial e o neocolonial, o apartheid, o trabalho forçado e o trabalho escravo, a eliminação extrajudicial, a tortura, a guerra permanente, a acumulação primitiva de capital, os campos de internamento para refugiados, a dronificação do conflito militar, a vigilância de massas, o racismo, a violência doméstica, o feminicídio. (SANTOS, 2019 p. 42 e 44, grifo nosso).

A Cartografia na Escola Zico Coelho não se faria alheia à "linha abissal" que divide humanos e subhumanos. Se, na escola, havia um acordo tácito de que todos são humanos e aquele coletivo preza por uma "sociabilidade metropolitana", não se pode garantir o mesmo no regresso dos estudantes a suas casas e ao trabalho. Mulheres, negros, jovens teriam sua humanidade resguardada ao cruzar a linha abissal, adentrando à lógica própria da "sociabilidade colonial" corporificada por patrões, policiais, cônjuges violentos?

Como exercício preparatório da oficina, os estagiários foram desafiados a traçar cartografias (Figuras 4) de grupos minoritários no município de Itapuranga, potenciais habitantes do outro lado da linha abissal. Foram sugeridos os seguintes grupos: Homossexuais, Carroceiros, Costureiras e Feirantes. Cada grupo era livre para definir a natureza de suas representações.

Figura 4 - UEG/Unu de Itapuranga (GO): oficina preparatória, 2019

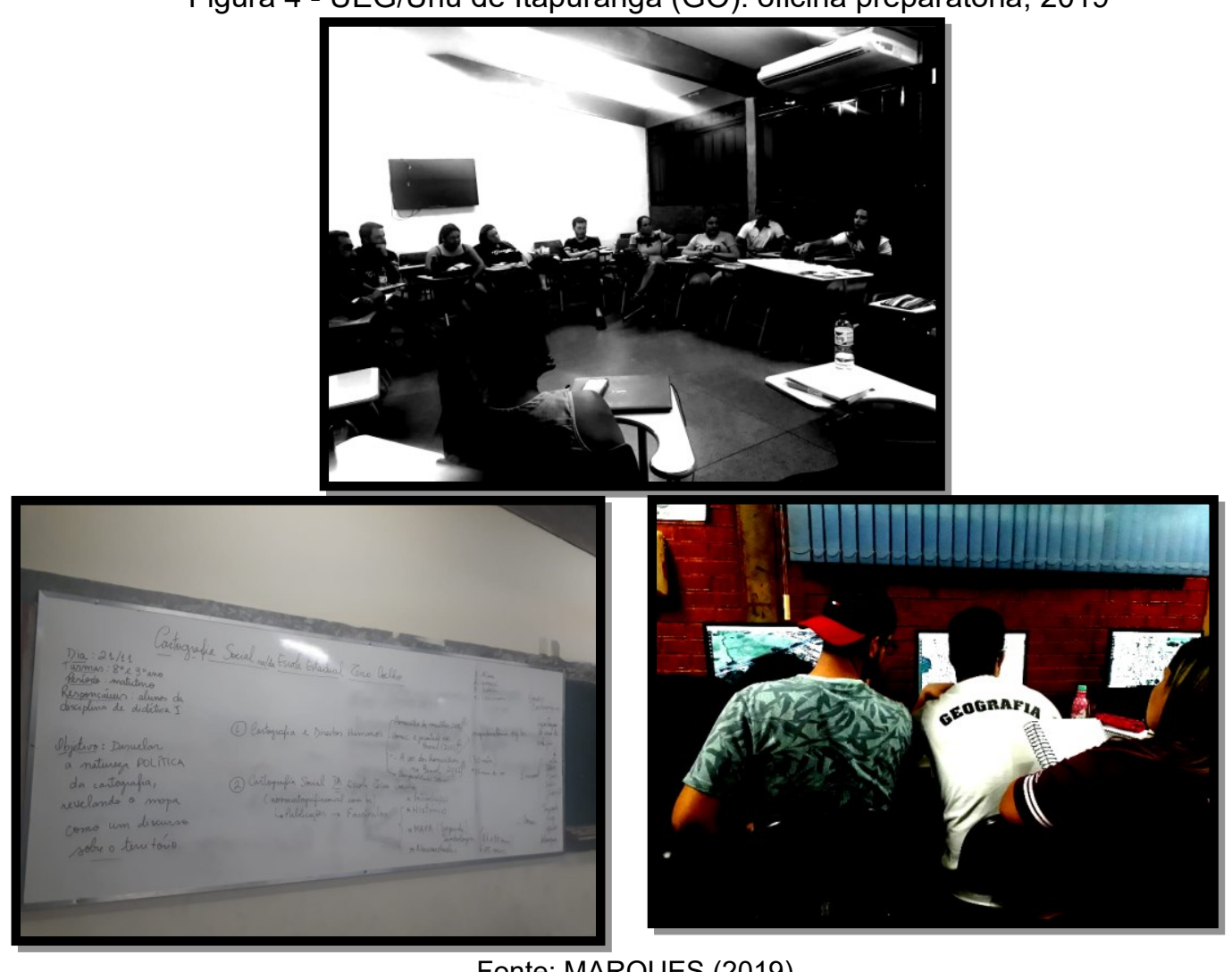

Fonte: MARQUES (2019).

Alguns estagiários recorreram ao Google Maps para extrair a base cartográfica sobre a qual traçariam os trajetos literais dos grupos analisados, enquanto outros exploraram a literatura, a fotografia e os desenhos como dispositivos de representação. Da avaliação coletiva dessa experiência, definimos os materiais e procedimentos que mobilizaríamos na oficina "oficial". 


\section{A OFICINA "CARTOGRAFIA E DIREITOS HUMANOS" NA ESCOLA ESTADUAL ZICO COELHO - ITAPURANGA(GO)}

Oito da manhã do dia vinte e um de novembro de 2019. Orientadora, professor-regente, estagiários e secundaristas (do $8^{\circ}$ e $9^{\circ}$ anos do ensino fundamental) dão início à oficina "Cartografia e Direitos Humanos" na Escola Estadual Zico Coelho. Cumpria-se ali, parte considerável da regência, agora não mais restrita à atuação individual do estagiário na imitação de modelos de ensino.

Mais de quarenta anos em funcionamento, esta escola pública sobrevive a um processo de militarização e privatização da educação no Estado de Goiás. Com infraestrutura inferior a outro colégio estadual da cidade, recentemente militarizado, o Zico Coelho acolhe os estudantes que, por diversos motivos, especialmente socioeconômicos, não se encaixaram no "militar".

O professor regente que nos acompanha, por princípio ético-político, se recusa a migrar para a escola militar, tampouco seria aceito devido à sua atuação no movimento docente. Aliás, sua postura e compreensão de mundo foram determinantes na implementação das novas práticas no nosso estágio supervisionado.

Com o referencial teórico-metodológico amadurecido nas orientações extraclasse e nas aulas de Didática, os estagiários dispunham ainda de dados extraídos da série "Mapa da Violência", folhetos com mapas anamórficos ${ }^{4}$, bases cartográficas impressas ${ }^{5}$, isopor, cartolinas, pincéis, computador e projeto multimídia.

A oficina se dividiu em duas partes. Dedicamos a primeira parte (Figura 5), "Cartografia e Direitos Humanos" à sensibilização dos secundaristas através de mapas e dados da violência, vista sob quatro perspectivas: 1. Feminicídio; 2. Homicídio de jovens; 3 Homicídio de negros; 4. Violência sistêmica: segregação socioespacial. Esta última cumpria o propósito de expandir a compreensão dos direitos humanos para além do campo penal/judiciário.

Figura 5 - Itapuranga (GO): primeira parte da oficina "Cartografia e Direitos Humanos" na Escola Estadual Zico Coelho, 2019.

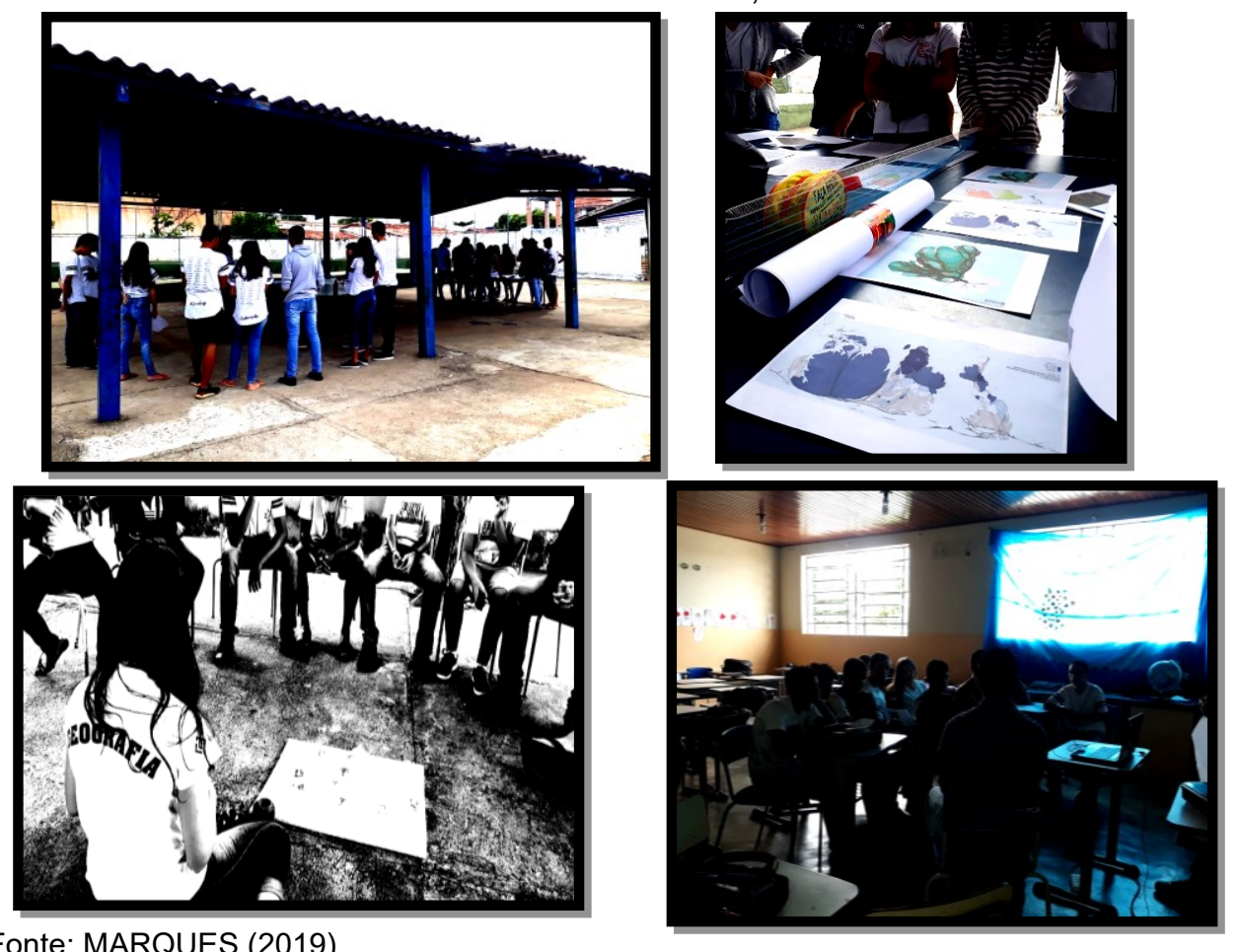

Fonte: MARQUES (2019).

\footnotetext{
${ }^{3}$ Série coordenada pelo sociólogo Julio Jacobo Waiselfisz, coordenador de estudos sobre a violência da Faculdade Latino-Americana de Ciências Sociais (FLACSO/BRASIL). Disponível em:

https://www.mapadaviolencia.net.br/

${ }^{4}$ Extraídos do site https://worldmapper.org/

${ }^{5}$ Extraídas do https://www.google.com.br/maps
} 
$\mathrm{Na}$ primeira parte, os secundaristas foram divididos em quatro grupos. As dinâmicas aconteciam simultaneamente na sala de aula, no corredor e no pátio da escola. Cada grupo elegeu um relator das atividades.

A parte I não se encerrava na exposição dos dados e mapas. Os estagiários socializaram matérias jornalísticas coletadas em sites, blogs e jornais avaliados previamente quanto à confiabilidade das fontes. Desde jornais locais, regionais aos de circulação nacional. A ideia era saltar qualitativamente do dado estatístico à narrativa, do genérico ao concreto e cotidiano.

No grupo que tratou do feminicídio, por exemplo, os secundaristas liam parte da história de vida das vítimas e as localizavam na base cartográfica de isopor. O mapa foi se conformando com fotografias de rostos de mulheres cujas vidas foram interrompidas pela violência.

Uma pausa, aliás, para um acontecimento que ocorreu neste grupo: um garoto interrompeu a dinâmica e leu um texto anônimo, repleto de xingamentos endereçados às mulheres. No último fragmento, um apelo para que o texto fosse compartilhado com o maior número possível de leitores. Aquele pequeno texto, composto de palavras-ódio, ilustra o conceito de "sub-humano" para o qual chama atenção Boaventura Santos, e sua presença mesmo nos territórios "metropolitanos".

Reunidos na sala de aula, os relatores expuseram o conteúdo debatido em cada grupo e encerramos com a leitura de artigos da Declaração Universal dos Direitos Humanos (ONU, 1958).

A parte II (Figura 6) consistiu em atividade prática: a Cartografia Social da Escola Zico Coelho, construída segundo parâmetros/legenda elencados pelos próprios secundaristas.

Figura 6 - Itapuranga (GO): segunda parte da oficina "Cartografia e Direitos Humanos" na Escola Estadual Zico Coelho, 2019.

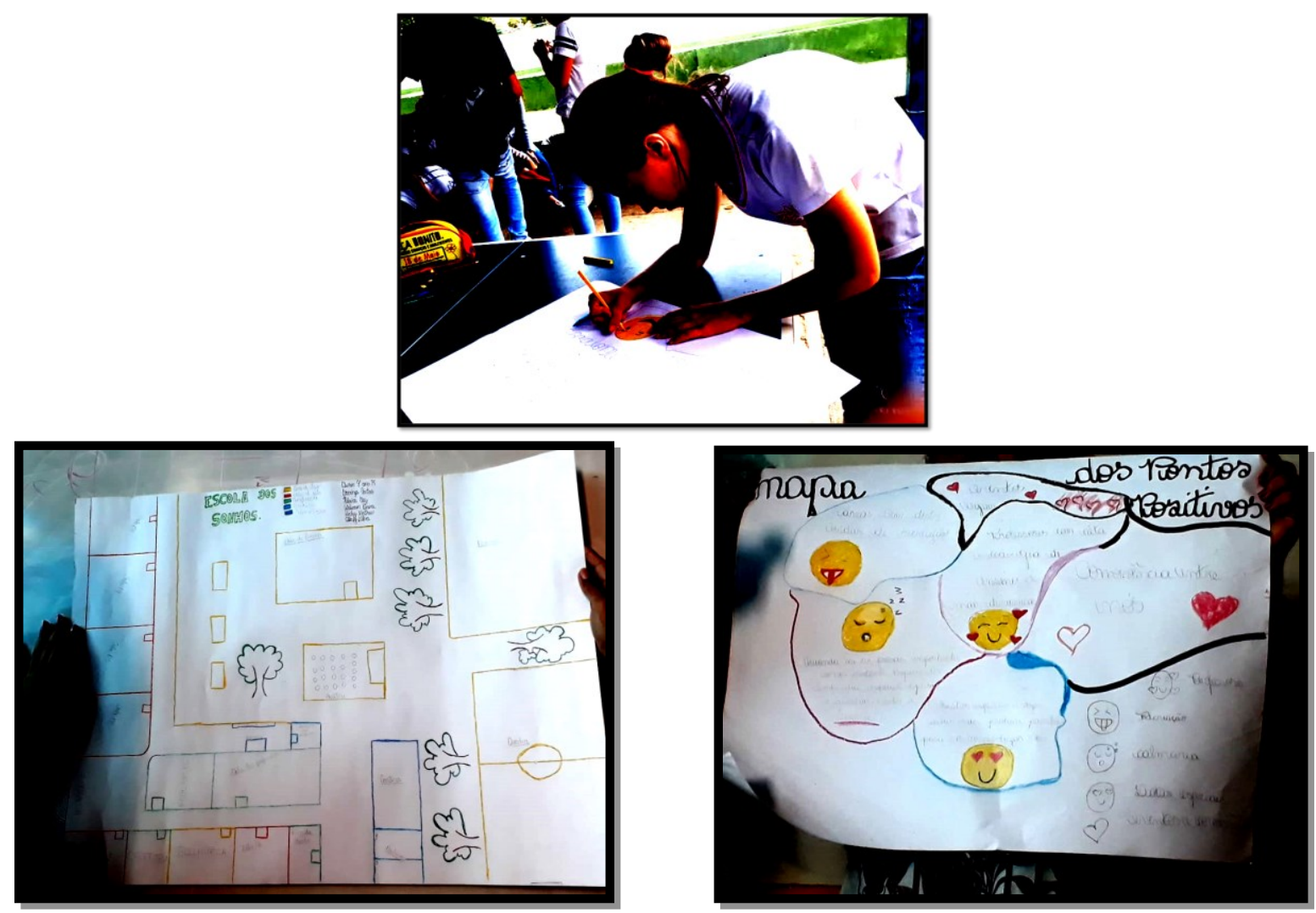

Fonte: MARQUES (2019). 
$\mathrm{Na}$ construção dos mapas, longos debates acerca da forma e do conteúdo a ser representado o espaço escolar. Houve grupos que construíram o mapa coletivamente, outros que elegeram um entre os vários confeccionados.

A princípio, os secundaristas se mostraram preocupados com a escala, temerosos de que o mapa não "coubesse" na cartolina. Lembrados de que a cartografia é uma representação do real e não o real em si, e que tinham a liberdade para fugir às convenções cartográficas que lhes parecessem limitadoras, os mapas começaram a ganhar cores, desenhos, versos.

A representação euclidiana do espaço escolar foi, por um grupo, substituída por uma representação descompromissada com a forma, recorrendo aos "emojis": ideogramas que representavam sentimentos e sensações associadas aos espaços da escola.

A parte II da oficina também se encerrou com a socialização dos produtos entre os integrantes de todos os grupos. Neste momento, algumas narrativas dos secundaristas surpreenderam o professor-regente que os assistia: "a biblioteca é o lugar do castigo"; "a escola dos sonhos é o Zico Coelho reformado, com quadra nova, pátio, árvores"; "não gostamos das grades, não somos loucos nem bandidos"; "queríamos mais aulas fora da sala".

Os secundaristas compreenderam também, ao longo da dinâmica, o valor estratégico de algumas informações e recusaram a cartografá-las. Foi o que aconteceu, por exemplo, com o "lugar do namoro" e o "ponto de fuga" da escola, retirados do mapa final.

A oficina foi encerrada sob aplausos ovacionais.

\section{CARTOGRAFIA DE UM FINAL PROVISÓRIO}

Relatamos, neste texto, a intervenção pedagógica de estagiários do $6^{\circ}$ período de licenciatura em Geografia (UEG) na Escola Estadual Zico Coelho (Itapuranga, GO), junto a secundaristas do $8^{\circ} \mathrm{e}$ $9^{\circ}$ ano do ensino fundamental.

As atividades preparatórias, ou de pesquisa, transcorreram em três espaço-tempos: 1. Trabalhos de campo na escola; 2. Elaboração do projeto de intervenção nas orientações Extraclasse; 3. Leitura, discussão de texto e "experimentações cartográficas" na disciplina "Didática e Prática de ensino em Geografia" (Ensino Fundamental). Prezou-se, em todos estes momentos, pela construção coletiva do referencial teórico, dos procedimentos metodológicos, da seleção do material, das formas de registro e avaliação da oficina.

A intervenção pedagógica fora composta por dois momentos. No primeiro deles, divididos em grupos, os secundaristas e estagiários debateram acerca da violência (física, emocional e sistêmica) endereçada às minorias políticas. No momento seguinte, os secundaristas foram provocados a representarem o espaço escolar sem, contudo, serem "fiéis" à geometria euclidiana.

Longe de apontar resultados rígidos ou receituários, compartilhamos alguns aprendizados dessa intervenção pedagógica:

1. A almejada interação dialética entre teoria e prática no estágio docência, só nos parece possível a partir do trabalho coletivo entre os atores da Educação Básica e da Universidade;

2. A condução atomizada/individualizada de estágio corrobora com uma compreensão fragmentada do fenômeno educacional, que além de "naturalizar" a aula como unidade básica de ensino, desconsidera o campo de forças territoriais (o mundo do trabalho, a captura da subjetividade, a privatização etc.) que extrapola a escola, porém incide fortemente sobre o processo educacional formal;

3. Prezamos pela observação ativa/participante da realidade escolar e rechaçamos a contemplação passiva pelos estagiários. Mais que a metodologia do professor, a observação supõe um processo de pesquisa de 
todos os componentes envolvidos na prática escolar, com ênfase nos sujeitos - e seus dramas - e a função social da escola nos territórios;

4. A cartografia a serviço dos direitos humanos situa o humano na centralidade do processo cartográfico, valorizando as narrativas - para além dos dados estatísticos - e as múltiplas escalas de percepção e valoração do espaço;

5. Uma educação que ofereça aos trabalhadores as ferramentas para se entenderem vítimas das injustiças sociais que lhes forjam sujeitos sem direito a ter direitos, desvenda a engrenagem por trás dos mecanismos de silenciamento e negação de coletivos e formas de vida segregadas;

6. A formação de professores afirmativa do vínculo entre educação e justiça social se faz sensível ao sofrimento de coletivos condenados a um "viver provisório" ou a "itinerários humanos" marcados pela desigualdade social. Organiza os processos pedagógicos a partir dos sujeitos concretos, de seus corpos, suas dores, suas lutas, de seus sorrisos apesar de...

Enfim, o estágio supervisionado, uma vez compreendido enquanto campo do conhecimento, abre-se a experimentações pedagógicas a exemplo da oficina "Cartografia e Direitos Humanos", necessárias à produção de teorias materialistas do ensino e a uma formação de professores sensível às particularidades dos territórios e sujeitos concretos.

\section{REFERÊNCIAS}

ANDERSON, Benedict. Comunidades imaginadas: reflexões sobre a origem e a difusão do nacionalismo. São Paulo: Companhia das Letras, 2008.

ARROYO, Miguel G. Passageiros da noite: do trabalho para a EJA: itinerários pelo direito a uma vida justa. - Petrópolis, RJ: Vozes, 2017.

CHAVEIRO, Eguimar Felício; DE VASCONCELLOS, Luiz Carlos Fadel. Ponte ao mundo: inserções espaciais da pessoa com deficiência. Pegada: A Revista da Geografia do Trabalho, v. 17, n. 2, 2016. Disponível em: https://revista.fct.unesp.br/index.php/pega da. Acesso em: fev. 2020. https://doi.org/10.33026/peg.v17i2.4519

DECLARAÇÃO UNIVERSAL DOS DIREITOS HUMANOS. Assembleia Geral das NaçõesUnidas em Paris. 10 dez. 1948. Disponível em: <http://www.dudh.org.br/wpcontent/uploads /2014/12/dudh.pdf>.

FREIRE, Paulo. Pedagogia do Oprimido. - 64 ed. - Rio de Janeiro/São Paulo: Paz e Terra, 2017.

GIRARDI, Gisele. A Aventura de ler mapas. In: SEEMANN, Jörn (Org.). A Aventura Cartográfica: Perspectivas, Pesquisas e Reflexões sobre a Cartografia Humana. Fortaleza, Expressão Gráfica, 2005/2006, 224 p.

KATUTA, Ângela Massumi. A linguagem cartográfica no Ensino Superior e Básico. In: PONTUSCHKA, Nídia N. e OLIVEIRA, Ariovaldo U. (orgs.). Geografia em Perspectiva: ensino e pesquisa. São Paulo: Contexto, 2009. p. 133-139.

OLIVEIRA, Hélvio Frank de; FIGUEIREDO, Francisco José Quaresma. O que os "não" nos diz: narrativas de licenciados em Letras que não se tornaram professores. In: OLIVEIRA, Hélvio Frank de; BICALHO, Poliene Soares dos Santos; MIRANDA, Sabrina do Couto de Miranda. (orgs.). Educação e Diversidade: múltiplos olhares. Anápolis: Universidade Estadual de Goiás, 2013.

PIMENTA, Selma Garrido; LIMA, Maria Socorro Lucena. Estágio e docência: diferentes concepções. Revista Poiésis -Volume 3, Números 3 e 4, pp.5-24, 2005/2006. Disponível em: https://s3.amazonaws.com/academia.edu.documents. Acesso em: mar. 2020. 
REGO, Nelson; COSTELLA, Roselane Zordan. Educação geográfica e ensino de Geografia, distinções e relações em busca de estranhamentos. Revista Signos Geográficos, v. 1, p. 15-15, 2019. Disponível em: https://www.revistas.ufg.br/signos/article/view/59454. Acesso em: fev. 2020.

SANTOS, Boaventura de Sousa. 0 fim do Império cognitivo: a afirmação das epistemologias do Sul. - 1 ed. - Belo Horizonte: Autêntica Editora, 2019.

TIBURI, Marcia. Feminismo em comum: para todas, todes e todos. Editora Record, 2018.

Recebido em: 20/09/2020

Aceito para publicação em: 21/11/2020 